\section{Screening sperm donors for cystic fibrosis}

EdIToR,-Cystic fibrosis is the most common serious autosomal recessive condition in white populations, affecting about 1 in 2500 live births, and until recently life expectancy rarely exceeded 30 years. The most common cystic fibrosis mutation $(\Delta \mathrm{F} 508$, accounting for about $80 \%$ of two million British carriers), is a 3-bp deletion in a transmembrane protein cystic fibrosis transmembrane regulator gene. The next most common three or four mutations account for a further $5 \%$ of carriers.

One in 25 white people carries cystic fibrosis. As carriers are unaffected, individuals are often unaware until they have an affected child.

Sperm donors are currently questioned for a famly history of genetic and other disorders (including cystic fibrosis) and tested for a variety of diseases. However, since few carriers have a family history of cystic fibrosis ${ }^{1}$ and as donors are currently not screened for cystic fibrosis, there is a potential problem.

If a donor is a cystic fibrosis carrier there is a high risk of this leading to at least one offspring being affected with cystic fibrosis and several being carriers-as a maximum of 10 can be fathered by each donor, the risk is 1 in 3 that a child will be affected (probability $\left.=1-(24 / 25)^{10}\right)$. The risk of an individual pregnancy being affected is increased 25 -fold (from 1 in 2500 to 1 in 100). If sperm were screened for the most common cystic fibrosis mutations and only proved non-carriers used, the risk would be reduced sixfold (to 1 in 14000)

To determine if cystic fibrosis screening for donors is effective, we retrospectively tested sperm samples from our donor sperm programme. Since $\Delta \mathrm{F} 508$ accounts for $85 \%$ of carriers in the Yorkshire region, we screened only for this mutation. Although screening is normally performed on blood or mouthwash samples, ${ }^{2}$ we tested the sperm samples themselves. To avoid the remote possibility that sperm preparation would preferentially select unaffected sperm, samples were treated in a similar manner (using Percoll gradients) to those used in in vitro fertilisation procedures. The DNA amplification methods were similar to those used in sexing and cystic fibrosis diagnosis of single cells using fluorescent polymerase chain reaction. ${ }^{3}$

The sperm from 22 prospective and current donors were tested. Two donors were found to carry cystic fibrosis $\Delta \mathrm{F} 508$. Both were prospective donors and were removed from stock.

Screening for cystic fibrosis in sperm donors is currently inadequate; we recommend that donors be routinely tested for cystic fibrosis. This testing is both effective and inexpensive (under $£ 25$ for $\Delta \mathrm{F} 508$ or about $£ 50$ for the commonest four mutations). One other consideration is possible medicolegal implications-that is, the exposure of parents to an unnecessary high risk of having a child affected with cystic fibrosis.

AN FINDLAY Research fellow HOWARD CUCKLE Professor of reproductive epidemiology RICHARD J LILFORD

Chairman of epidemiology and health services research Institute of Epidemiology and Health Services Research, University of Leeds, Leeds LS2 9LN

ANTHONY J RUTHERFORD PHILIP QUIRKE

Head of histopathology and molecular pathology Leeds General Infirmary, Leeds,

LS1 3EX

STEVEN LUI

IVF Unit,

Princess Royal Hospital,

Hull HU8 9HE

1 Holloway S, Brock DJH. Cascade testing for the identification of carriers of cystic fibrosis. Fournal of Medical Screening 1994;1 159-64.
2 Lewis FA, Cross P, Sehmi I, Cuckle H, Quirke P. Population screening for the cystic fibrosis gene using fluorescent PCR. f Pathol 1993;170:34A.

3 Findlay I, Ray P, Quirke P, Rutherford AJ, Lilford R. Allelic dropout and preferential amplification in single cells and human blastomeres: implications for preimplantation diagnosis of sex and cystic fibrosis. Human Reproduction (in press).

\section{Dornase alfa for cystic fibrosis}

\section{Patients should not be denied a safe, effective treatment}

EDITOR,-We were interested to read a paper in the Drug and Therapeutics Bulletin on dornase alfa, and as the clinicians in the United Kingdom with the most experience with dornase alfa we must profoundly disagree with the paper's conclusions that, on the evidence available, dornase alfa should not be added to the formulary. The trouble with any unsigned recommendation is that readers do not know how many clinicians with experience of cystic fibrosis, treatment with dornase alfa, or both, were responsible for the final draft. Similarly they cannot judge whether considerations of cost were paramount.

We have seen many patients improve considerably with this treatment, and in many cases there has been an improvement of more than $10 \%$ in pulmonary function. The paper seems to have missed several important points.

Firstly, the licensing authorities-the Food and Drugs Administration in the United States, the Committee for Proprietary Medicinal Products in the European Union, and the Medicines Control Agency in the United Kingdom-reviewed all the clinical trial evidence for safety and efficacy and, unlike the paper, which reviewed one study, recommended the drug for licensing.

Secondly, most patients with cystic fibrosis treated by conventional methods show a decline in lung function year on year, so any stabilisation is a gain and improvement in lung function a bonus. Data have been presented at conferences, but are not yet published, showing that lung function is still above baseline values after 21 months' treatment with dornase alfa.

Thirdly, a double blind clinical trial has now shown that patients who are severely ill (forced vital capacity-not forced expiratory volume in one second as stated in the paper- $<40 \%$ predicted) show a significant improvement in lung function after three months' treatment. This data was offered to the Drug and Therapeutics Bulletin.

Fourthly, many very ill patients with cystic fibrosis die on transplant waiting lists due to the lack of donor organs. The cyclosporin used to treat many cystic fibrosis patients after transplant operations costs more per day than dornase alfa. In our opinion it seems reasonable to use resources on treatment to prevent deterioration in lung function.

Fifthly, a consensus conference of doctors experienced in treating cystic fibrosis and in using dornase alfa was convened by the Cystic Fibrosis Foundation in the United States. It recommended dornase alfa for cystic fibrosis patients with inflammatory disease in the lower airway, ${ }^{2}$ and a working party of the Cystic Fibrosis Trust in Britain also concluded that dornase alfa had a role in the treatment of cystic fibrosis. The conclusions drawn by the authors of the article in the Drugs and Therapeutics Bulletin are unjustified and plays into the hands of non-medically qualified managers who wish to reduce the cost of treatment without understanding the issues.

As with any new treatment, survival data will not be available for a few years. In the meantime it is our opinion that patients with a life threatening disease-average age at death 26 years-should not be denied treatment with a drug that has been shown to be safe and in a number of studies not only to stabilise lung function but also improve it, reduce exacerbations of infection, and improve various measures of quality of life and also to effect a small reduction in some other costs of treatment. All patients who may benefit should have the opportunity to use this drug; in each case the clinician dealing with the case must decide whether there is enough benefit for treatment to be continued.

$\begin{array}{cr}\text { ANDREW BUSH } & \text { MARGARET E HODSON } \\ \text { Consultant paediatrician } & \text { Consultant physician } \\ \text { DUNCAN M GEDDES } & \text { MARK ROSENTHAL } \\ \text { Consultant physician } & \text { Consultant paediatrician } \\ \text { Royal Brompton Hospital, London SW3 6NP } \\ \text { ROBERT DINWIDDIE } \\ \text { Consultant paediatrician } \\ \text { Consultant paediatrician } \\ \text { Hospital for Sick Children, }\end{array}$

Great Ormond Stre

DAVID E STABLEFORTH Consultant physician

Heartlands Hospital, Birmingham

STEVEN P CONWAY

Seacroft Hospital, Leeds

Consultant physician and paediatrician

St James's University Hospital, Leeds

AMES M LITTLEWOOD Consultant paediatrician

1 Dornase alfa for cystic fibrosis. Drug and Therapeutics Bulletin 1995;33(2):15-6.

2 Ramsay BW, Dorkin HL for Consensus Committee. Consensus

conference: practical applications of pulmozyme. Pediatric Pulmonology 1994;17:404-8.

Margaret E Hodson, Andrew Bush, and Mark Rosenthal have all undertaken research projects that were funded by Genentech, the manufacturers of dornase alfa. Robert Dinwiddie and Colin Wallis work in the respiratory unit a Great Ormond Street. The department contributes to an international database being assembled by GenentechRoche. The company pays money to the department, which is used to fund other related cystic fibrosis research. David E Stableforth is currently negotiating a research project and grant with Genentech. Steven P Conway's department is participating in the Genentech-Roche cystic fibrosis database.

\section{Evidence supporting use of this drug has not yet been published}

EDITOR,- There have been several instances of drugs being approved by licensing authorities and later shown to be clinically ineffective. Many vasodilators used for the treatment of periphera vascular disease or dementia are still licensed in the United Kingdom (and probably elsewhere) but their clinical value is questionable.

Bush and colleagues refer to the outcome of a consensus conference. The article in the Drug and Therapeutics Bulletin' refers to findings of the Australian Pharmaceutical Benefits Advisory Committee, which concluded that dornase alfa "produces little benefit for patients with cystic fibrosis." More recently, PHARMAC, the New Zealand drugs subsidy agency, has come to the same conclusion.

The key works which seem to have determined Bush et $a l$ s stance have not yet been published. The Drug and Therapeutics Bulletin would be happy to revise its position if the data, once published, warrant it. If anything, the Bulletin's position was strengthened by a recent publication from two of the signatories. ${ }^{4}$ Their six month study indicates that in patients given dornase alfa the small increases in forced expiratory volume in one second and forced vital capacity $(6 \%$ and $7 \%$ respectively) were not associated with any improvement in the severity of dyspnoea, general well being, symptoms related to cystic fibrosis, intercurrent illness, or the sort of adverse events expected in a cystic fibrosis population. In the absence of such improvements, and while there is no evidence that dornase alfa prevents the development of progressive lung damage, ${ }^{5}$ it would seem sensible to continue to consider the drug as essentially experimental. 